\title{
Rate of Complications and Conversions After Laparoscopic and Open Cholecystectomy
}

Hajrudin Halilovic', Sefik Hasukic ${ }^{2}$, Ervin Matovic ${ }^{2}$, Goran Imamovic ${ }^{3}$

Department of Surgery, Cantonal Hospital Bihac, Bosnia and Herzegovina ${ }^{1}$

Department of Surgery, University Clinical Center Tuzla, Faculty of Medicine,

University of Tuzla, Tuzla, Bosnia and Herzegovina ${ }^{2}$

Dialysis Center Zvornik, Zvornik, Bosnia and Herzegovina ${ }^{3}$

ackground and objectives: Although many advantages of laparoscopic method in regard to open one have been already proved, both surgical methods may cause a certain number of complications. The goal of the study is to answer the question: Is Laparoscopic Cholecystectomy (LC) safer and more satisfactory method than open cholecystectomy (OC) concerning number, type and seriousness of complications? Design and Setting: Prospective, the research includes all patients in Bihać Cantonal Hospital during 2007, who had cholecystectomy, laparoscopic or open, because of the gallbladder calculosus. Methods: The study has included 476 patients who had cholecystectomy and who satisfied standards for this study. Of the total number of patients, 293 of them had laparoscopic cholecystectomy and 183 open cholecystectomy. Total number of complications is established for each group of patients. Results: The study has shown that there were more complications in patients operated by open method than in those operated by laparoscopic cholecystectomy $(\mathrm{p}<0.0001)$. Intraoperative bleeding was found in $1.63 \%$ of patients with open and $0.68 \%$ with laparoscopic cholecystectomy. Postoperative collection in abdomen were found in $2.18 \%$ of patients with open and $1.02 \%$ with laparoscopic method. The most common complications for open cholecystectomy were: infection (2.73\%), hematoma in the wound $(2.73 \%)$ and urine retention (2.18\%). Conclusion: It can be concluded that LC and OC are comparable procedures for the treatment of gall stone disease in terms of complications, results of this study demonstrate that LC is essentially a safe procedure with low complicatins, morbidity and mortality rate. KEY WORDS: LAPAROSCOPIC CHOLECYSTECTOMY, OPEN CHOLECYSTECTOMY, COMPLICATIONS, CONVERSIONS.

Correspondning author: prof Sefik Hasukic, MD, PhD. University Clinical Center, Department of Surgery. Trnovac b.b. 75000 Tuzla, B\&H. Phone.+387 35238 357. Fax.: +387 35250 474. E-mail: shasukic@bih.net.ba

\section{INTRODUCTION}

Laparoscopic cholecystectomy (LC) stands for a gold standard for the treatment of gall stone disease. Open cholecystectomy has been the gold standard of treatment for cholelithiasis for more than 100 years. Since then, due to growing experience and development of specially adapted laparoscopic instruments the technique has improved immensely (1). In the case of intraabdominal adhesions, perforated gallbladder, untypical or uncertain anatomy, or when intraoperative complications occur and it's impossible to manage them laparoscopiacaly, open method is still indicated $(2,3)$. However, laparoscopic cholecystectomy has revolutionized our approach to a number of problems and caused a reevaluation of clinical strategies. It is associated with minimal risk to the patient and a high degree of relief from symptoms. Now it has become the standard therapy for symptomatic gall stone disease, particularly in elective setting $(4,5)$. According to several studies some advantages of laparoscopic over open surgery are related to: the reduction in trauma of access without compromising the operative field, reduction of postoperative pain, reduction in incidence of wound infection, reduction of recovery time, duration of hospitalization and return to normal diet, activity and work, better cosmetic appearance. Although many advantages of laparoscopic method in regard to open one have been already proved, both surgical methods may cause a certain number of complications. However, comparing complications after the laparoscopic cholecystectomy and the open one is not just listing the complications of these two methods, it is the correct disposition of complications into comparable groups.

The aim this study is establish number, kind and difficulties of complications resulting after laparoscopic and conventional (open) cholecystectomy.

\section{PATIENTS AND METHODES}

The study is retrospective and includes all patients who underwent cholecystectomy (laparoscopic or open) 


\begin{tabular}{|l|l|}
\hline Complication grade & Complications description \\
\hline Grade 1: & $\begin{array}{l}\text { Deviation from the ideal postoperative course, } \\
\text { non-life threatening with no lasting disability e.g. prolonged stay due to } \\
\text { ileus, fever, wound infection, urinary tract infection, pulmonary infection } \\
\text { and costochondritis. }\end{array}$ \\
\hline Grade 2a: & $\begin{array}{l}\text { Potentially life threatening but without residual disability eg., cholangitis, } \\
\text { retroperitoneal hematoma, subhepatic collection, pancreatitis. }\end{array}$ \\
\hline Grade 2b & $\begin{array}{l}\text { Potentially life threatening but without residual disability, but surgery was } \\
\text { necessary to restore } \\
\text { health e.g., bile duct injury, duodenal perforation, retained stones, bile } \\
\text { leak, bleeding, gastrointestinal injury, bladder injury. }\end{array}$ \\
\hline Grade 3 & $\begin{array}{l}\text { Uncontrolled bleeding or shock; laceration of } \\
\text { aorta, hepatic artery, mesenteric vein, portal vein injury, perforated iliac } \\
\text { artery or vein. }\end{array}$ \\
\hline Grade 4 & Death due to complications \\
\hline
\end{tabular}

TABLE 1. Complications after conventional (open) and laparoscopic cholecystectomy divided into separated groups (7)

due to calculosus gallbladder, at the Surgical Department, Bihać Cantonal Hospital, in 2007. The study has included 476 patients who had cholecystectomy and who satisfied standards for this study. Of the total number of patients, 293 of them had laparoscopic cholecystectomy and 183 open cholecystectomy. Studies including criterias were: laparoscopic or conventional (open) cholecystectomy performed in 2007, cholecystectomy caused by acute or chronic inflamation of the gallbladder caused by calculosus, medical patients history, physical examination, laboratory testing and ultrasonographic evaluation of the gallbladder, permanent postoperative follow up

Excluding criteria were: patohistological conformation of gallbladder carcinoma, which was not noticed during operations, cholecystectomy performed during other abdominal surgery procedures. The statistical analyses were conducted according to kind, number and appearing time of intra and/or post operative complications. Total number of complications is established for each group of patients. According to type and seriousness, the complications are divided into four basic groups $(6,7)$.

The statistical analyses were conducted using Microsoft Excel 2007, Biostat 2008 and MedCalc software's. Incidence comparations between laparoscopic and conventional

\begin{tabular}{|l|l|l|l|}
\hline Comlication grade & $\begin{array}{l}\mathrm{OH}(\%) \\
(\mathrm{n}=183)\end{array}$ & $\begin{array}{l}\mathrm{LH}(\%) \\
(\mathrm{n}=293)\end{array}$ & $p$ \\
\hline 1 & 9.83 & 5.8 & NS \\
\hline $2 \mathrm{a}$ & 9.29 & 2.73 & 0.0036 \\
\hline $2 \mathrm{~b}$ & 9.83 & 5.8 & NS \\
\hline 3 & 1.09 & 0.34 & NS \\
\hline 4 & 0.55 & 0.34 & NS \\
\hline Total & $56(30.6)$ & $44(15.02)$ & 0.0001 \\
\hline
\end{tabular}

TABLE 2. Complications distribution depending of operating method

\begin{tabular}{|l|l|l|l|}
\hline Complication & $\mathrm{OH} 35 / 183$ & LH 25/293 & $\mathrm{p}$ \\
\hline Wound infection & $5(2.73)$ & $1(0.34)$ & $\mathrm{NS}$ \\
\hline Hematoma & $5(2.73)$ & $1(0.34)$ & $\mathrm{NS}$ \\
\hline Seroma & $1(0.54)$ & $2(0.68)$ & $\mathrm{NS}$ \\
\hline Urinary retention & $4(2.18)$ & $4(1.36)$ & $\mathrm{NS}$ \\
\hline Lung atelectasys & $1(0.54)$ & $0(0.0)$ & $\mathrm{NS}$ \\
\hline Pain & $2(1.09)$ & $9(9.56)$ & 0.0005 \\
\hline Haemorrhagy & $3(1.63)$ & $2(0.68)$ & NS \\
\hline Bile leack & $5(2.73)$ & $2(0.68)$ & NS \\
\hline Pleuritis & $1(0.54)$ & - & $\mathrm{NS}$ \\
\hline Pneumonia & $2(1.09)$ & - & NS \\
\hline Lung emboly & $1(0.54)$ & 1 & NS \\
\hline Thrombophlebitis & $1(0.54)$ & $1(0.34)$ & NS \\
\hline $\begin{array}{l}\text { Intraabdominal } \\
\text { colection }\end{array}$ & $4(2.18)$ & $3(1.02)$ & NS \\
\hline Total & $35(19.13)$ & $25(8.53)$ & 0.0012 \\
\hline
\end{tabular}

TABLE 3. The most present complications in both groups of cholecystectomised patients cholecystectomy were made using multivariant analysis using model of logistical regression and Mann Whitney's test. P value of $<0.05$ was considered statistical significant.

\section{RESULTS}

The study has included 476 patients who had cholecystectomy and who satisfied standards for this study. Of the total number of patients, 293 of them had laparoscopic cholecystectomy and 183 open cholecystectomy. Total number of complications is established for each group of patients. According to type and seriousness, the complications are divided into four basic groups. The study has shown (Table 2) that there were more complications in patients operated by open method than in those operated by laparoscopic cholecystectomy $(\mathrm{p}<0.0001)$.

Intraoperative bleeding was found in $1.63 \%$ of patients with open and 0,68 $\%$ with laparoscopic cholecystectomy. Postoperative abdomen collection were found in $2.18 \%$ of patients with open and $1.02 \%$ with laparoscopic method. The most common complications for open cholecystectomy were: infection ( $2.73 \%$ ), hematoma in the wound $(2.73 \%$ ) and urine retention (2.18\% ) (Table 3).

Conversion to laparotomy occurred in $8(9.2 \%)$ patients with acute cholecystitis and 16 (4.11\%) with chronic cholecystitis (Table 4). Mortality was higher in open cholecystectomy compared with laparoscopic technique $(\mathrm{p}<0.0001)$. It has been determined significantly higher occurrence of complications in patients operated by less experienced surgeons in both group.

\section{DISCUSSION}

Conventional (open) cholecystectomy has been the gold standard of treatment for calculus gallbladder for more than 100 years. Since 1986, when the first laparoscopic cholecystectomy has been made, new golden standard has established. Limited postoperative pain, excellent cosmetics, shorter recovery periods, reduction in hospitalization time, improved postoperative pulmonary function and reduction in hospital costs are the major advantages of this method.

In the beginning the new method 


\begin{tabular}{|l|l|l|l|}
\hline Caracteristic & $\begin{array}{l}\text { Acute } \\
\text { cholecystitis }\end{array}$ & $\begin{array}{l}\text { Chronic } \\
\text { cholecystitis }\end{array}$ & $p$ \\
\hline $\begin{array}{l}\text { OH }(n=183) \\
\text { LH }(n=293)\end{array}$ & $\begin{array}{l}43(23.5) \\
44(15.0)\end{array}$ & $\begin{array}{l}140(76.5) \\
269(75.0)\end{array}$ & $\begin{array}{l}<0.0001 \\
<0.0001\end{array}$ \\
\hline Total & $87(18.28)$ & $389(81.72)$ & \\
\hline Conversion(n=24) & $8(9.2)$ & $16(4.11)$ & NS \\
\hline $\begin{array}{l}\text { Mortality } \\
\text { OH }(n=2) \\
\text { LH }(n=1) \\
\text { Total mortality }\end{array}$ & $1(1.49)$ & $\begin{array}{l}1 \\
2(0.49)\end{array}$ & NS \\
\hline
\end{tabular}

TABLE 4- Conversion and mortality after laparoscopic and open cholecystectomy

was confronted with many problems. Operative time was much longer for laparoscopic cholecystectomy. Laparoscopic technique had higher operating cost than conventional open cholecystectomy. Many operative complications had occurred while performing laparoscopic operations in late ' 80 $(8,9)$. But soon it has been noticed that the method showed impressive learning curve and problems decreased rapidly with growing experience.

This study has included 476 patients who had cholecystectomy and who satisfied standards for this study. First degree of complication was determined in 35 (7.35\%) cases, the level of 2a was found in 25 (5.25\%) cases, the degree of complications $2 \mathrm{~b}$ is determined in 35 cases $(7.35 \%)$, level 3 in 3 cases $(0,63 \%)$, level 4 in 2 cases ( $0.4 \%)$. In 376 (78.99\%) were not identified any complications. It was significantly more postoperative complications in patients operated with open method $(p<0.0001)$. Mortality was higher in open cholecystectomy compared with laparoscopic technique (p $<0.0001)$. It has been determined significantly higher occurrence of complications in patients operated by less experienced surgeons in both group.

In general, numerous research studies established that the risk of occurrence of complications exists in both methods, but it is small and, comparing open and laparoscopic methods, no significant differences between these two techniques, or a mild advantage of laparoscopic methods has been found. Laparoscopic cholecistectomy in relation to open, has showed some of advantages such as shorter hospitalization and faster recovery time (10). Open cholecystectomy has long been the method of choice in the treatment of calculosus gallbladder. Mortality ranged from $0-0,5 \%$ in the case of elective surgery and major complications ranged up to $4.5 \%(11,12)$. At first the laparoscopic cholecystectomy was burdened with some serious complications such as bile tract injuries or major blood vessels, but soon this method completely replaced the open method technique $(1,13)$. Although it is very difficult to compare two methods, there are numerous studies that compare laparoscopic and open cholecystectomy.

Jatzko et all. found, according to their study, that laparoscopic cholecystectomy is far more favorable method comparing to open technique (7). Grupta et all. in 2009 divided possible complications into 4 groups, as has been done in this study. The frequency of complications in both groups operated was $4.8 \%$. Complications in 1 group (degree) have been for 1.89 times more frequently in open than in laparoscopic cholecystectomy. In group $2 \mathrm{~b}$ complications were 3.4 times more frequent in laparoscopic than in open technique (8). Other studies have confirmed approximately the same number of complications during laparoscopic and open cholecystectomy (2). The increased number of complications in our patients after open cholecystectomy, compared with laparoscopic, we can explain due to all difficult patients with associated risk factors, in who we decided to open surgery method. Indisputable fact is that the laparoscopic cholecystectomy presents reliable method and is especially advantageous for elective surgery.

The laparoscopic and open cholecystectomies have their own complications that need to be familiar with. It is necessary to take into account the present risk factors, which enables surgeons to reduce complications and make the method safer for the patient. It is the fact that the laparoscopic method is a reliable method and it has some advantages with elective operations. The increased number of complications after open cholecystectomy in regard to laparoscopic cholecystectomy, can be explained in a way that all serious patients with joined risk factors were operated with open method. Laparoscopic cholecystectomy is better method in operation and treatment of the gallbladder calculosus than open method, due to greater patient benefits.

\section{CONCLUSION}

It can be concluded that LC and $\mathrm{OC}$ are comparable procedures for the treatment of gall stone disease in terms of complications, results of this study demonstrate that LC is essentially a safe procedure with low complications, morbidity and mortality rate.

\section{REFERENCES}

1. Hasukić Š, Mešić D, Kadrić N, Hadžiselimović S. Complications in laparoscopic surgery Med Arh. 1998; 27(1-2): 103-108.

2. Keus F, deJong JA, Gooszen HG. Laparoscopic versus open cholecystectomy for patients with symptomatic cholecystolithiasis. Cochrane $\mathrm{Da}$ tabase of Systematic Reviews, 2006; Issue 4. Art. No. CD006231

3. Cawich SO, Mitchell DIG, Newnham MS, Arthurs M. A Comparison of Open and Laparoscopic Cholecystectomy done by a Surgeon in Training. West Indian Med J. 2006; 55(2): 103.

4. Hasukić Š, Mešić D, Dizdarević E, Hadžiselimović $S$, Bazardžanović M, Bojanic M, Reasons for reoperation after laparoscopic cholecystectomy. Med Arh. 2000; 54(1): 25-27.

5. Attwood SEA, Hill ADK, Mealy K, Stephens RB A prospective comparison of laparoscopic versus open cholecystectomy Annals of the Royal College of Surgeons of England. 1992; 74; 397-400.

6. Clavien PA, Sanabria JR, Strasberg SM. Proposed classification of complications of surgery with examples of utility in cholecystectomy. Surgery, 1992; 111: 518-526.

7. Jatzko GR, Lisborg PH, Pertl AM, Stettner HM Multivariate comparison of complications after laparoscopic cholecystectomy and open cholecystectomy. Ann Surg. 1995; 221(4): 381-386.

8. Grupta V, Chowdri N, Wani NA, Naqash S. LAP V/S Open Cholecystectomy: A Prospective Study of 800 Patients. JK Science. 2009; 11(1): 11-15.

9. Deziel DJ, Millikan KW, Economou SG, Doolas A, Ko ST, Airan MC. Complications of laparoscopic cholecystectomy:A national survey of 40292 hospitals and 77604 cases. Am J Surg. 1993; 165(1): 9-14.

10. Giger UF, Michel JM, Opitz I, Th Inderbitzin D, Kocher T, Krähenbühl L; SWALT Study Gropu. Risk factors for perioperative complications in patients undergoing laparoscopic cholecystectomy: analysis of 22,953 consecutive cases from the Swiss Association of Laparoscopic and Thoracoscopic Surgery database. J Am Coll Surg. 2006; 203(5):723-728.

11. Clavien P, Sanabria J, Mentha G, et al. Recent re sults of elective open cholecystectomy in a North American and a European center. Ann Surg. 1992 216: 618-626.

12. McSherry C. Open Cholecystectomy. Am J Surg. 1993; 165:435-439.

13. Jansen FW, Kapiteyn K, Trimbos-Kemper T, Hermans J, Trimbos JB. Complications of laparoscopy: a prosepctive multicentre observational study. Br J Obstet Gynaecol. 1997; 104: 595-600 